\title{
Early Career Experiences of Pediatricians Pursuing or Not Pursuing Fellowship Training
}

Bobbi J Byrne, MD${ }^{1}$, Shesha K Katakam, MD, $\mathrm{MPH}^{2}$, Mary Pat Frintner, $\mathrm{MSPH}^{3}$, and William L Cull, $\mathrm{PhD}^{3}$

Affiliations: ${ }^{1}$ Indiana University, Indianapolis, IN; ${ }^{2}$ Indiana University Health La Porte, La Porte, IN; and ${ }^{3}$ American Academy of Pediatrics, Elk Grove Village, IL.

Address correspondence to: Bobbi J Byrne, MD, Department of Pediatrics, Section of Neonatal-Perinatal Medicine, 699 Riley Hospital Drive, RR208, Indianapolis, IN, 46202, (317)274-4718, bjbyrne@iu.edu.

Short title: Early Career Experiences of Pediatricians

Abbreviations: PLACES - Pediatric Life and Career Experience Study

Key words: pediatric residents, career planning, pediatric workforce

Funding source: American Academy of Pediatrics

Financial disclosure: Drs. Byrne, Katakam, and Cull, and Ms. Frintner have no relevant financial relationships to disclose.

Conflict of Interest: Drs. Byrne, Katakam, and Cull, and Ms. Frintner have no conflicts of interest to disclose.

What's known on this subject: Choosing career paths can be difficult decisions for residents contemplating fellowship training. Limited resources are available to residents to help guide their choices.

What this study adds: This article provides additional descriptions and insight into actual lifestyle and workplace environments for those pediatric residents that choose fellowship training compared to those that do not.

This is the author's manuscript of the article published in final edited form as: 


\section{Contributor's Statement}

Bobbi J Byrne: Dr. Byrne conceptualized and designed the study, interpreted data, drafted and revised the manuscript, and approved the final manuscript as submitted.

Mary Pat Frintner: Ms. Frintner helped conceptualize and design the study, coordinated data collection, carried out analyses, interpreted data, reviewed and revised the manuscript, and approved the final manuscript as submitted.

Shesha K Katakam and William L Cull: Drs. Katakam and Cull helped conceptualize and design the study, interpreted data, reviewed and revised the manuscript for important intellectual content, and approved the final manuscript as submitted. 


\begin{abstract}
Background and Objectives: Choosing career paths can be difficult decisions for residents contemplating fellowship training. This study compares the experiences of early career pediatricians who did and did not pursue fellowships.

Methods: We analyzed national, weighted data from pediatricians 8-10 years post-residency $(n=842)$. Work environment, work-life balance, and satisfaction were compared for pediatricians who had pursued fellowship training (fellowship-trained) and those that did not pursue fellowship training (generalist-trained). Logistic and linear regression examined the independent effects of fellowship training while controlling for demographic differences.

Results: 39.0\% of the pediatricians (328/842) pursued fellowship training. The fellowshiptrained group was less likely than the generalist-trained group to spend time in direct patient care and more likely to report learning opportunities in their work environment. This group was also more likely to report an income of $\$ 150,000$ or higher, although no difference was found when only full-time pediatricians were examined. Generalist-trained pediatricians were more likely to work $<50$ hours/week, have flexibility with their schedules, and be satisfied with time spent with their own children. Pediatricians in both the fellowship-trained and generalist-trained groups generally found their work to be rewarding and were satisfied with their life.
\end{abstract}

Conclusion: While important life and career differences need to be considered by residents when contemplating fellowship training versus general care, overall life and career satisfaction can be achieved by pediatricians in both groups. 
Choosing a career path can be difficult for residents contemplating fellowship training. Limited resources are available to provide guidance. Information exists on characteristics of residents who are more likely to choose fellowship and factors that might contribute to this decision, but missing information includes what happens in their work and life after fellowship.

Certain subgroups of pediatricians have been found to be more likely to pursue subspecialty training. Males, international medical school graduates (IMGs), and residents from larger residency programs are more likely to undertake subspecialty training. ${ }^{1-4}$ Other related factors include market forces, indebtedness, mentor specialty, and work hours or the availability of part-time positions. ${ }^{3-6}$ Published research has directly asked pediatricians what led them to pursue or not pursue subspecialty training. Surveys of pediatric residents and early career pediatricians found structured hours and lifestyle were important factors to those who planned to pursue a career in general pediatrics. ${ }^{2,7}$ Interest in specific diseases and patient populations remained the most important factor in post-residency career choice for those residents planning to pursue fellowships. ${ }^{8,9}$

In the current study, our goal is to learn more about what happens in the work and life of pediatricians after fellowship. We examine the work environment, learning and financial characteristics, work-life balance and overall satisfaction among pediatricians early in their careers who did and did not pursue fellowship training.

\section{METHODS}

The American Academy of Pediatrics (AAP) Pediatrician Life and Career Experience Study (PLACES) is a national, longitudinal study that tracks the job paths and lives of early 
career pediatricians. In the current study, we only examined a single year of cross-sectional data from PLACES. ${ }^{10}$ We analyzed data collected in 2012 from a cohort of pediatricians completing residency between 2002-2004 to better understand the differences in career satisfaction and lifestyle of early career pediatricians who did and did not pursue fellowships.

\section{PLACES Description and Participants}

PLACES includes two cohorts of pediatricians: 1) 2002-04 Cohort who completed residency training from a categorical pediatric or pediatric combined training program between the years 2002-2004 and 2) 2009-11 Cohort who completed residency between the years 20092011. ${ }^{10}$ As many members of the 2009-11 Cohort were still in fellowship training at the time of the initial data collection, this paper includes analyses from only the 2002-04 Cohort; therefore, the following description and participants pertain only to these PLACES participants.

Pediatricians were identified using an AAP database that includes all pediatricians who completed a U.S. residency program, comprising both AAP members and non-members. An additional small group of pediatric surgical and other specialists were included based on membership in an AAP specialty section and having an age consistent with the cohort residency graduation years. ${ }^{10}$

Random samples of pediatricians were selected from the respective target pool and invited to participate in PLACES. ${ }^{10}$ A total of 2,495 pediatricians were contacted by mail and email; 969 were interested in participating and completed the study intake survey. The intake survey was administered (December, 2011 - April, 2012) as part of PLACES recruitment. The first main survey (Annual Survey 1) was conducted (May - August, 2012) via email and mail (up 
to 6 requests), depending on participant preference. Among those who completed their intake survey, 901 (93\%) completed Annual Survey 1. Participants received a \$20 Amazon gift card for completing Annual Survey 1.

For the current study, we used data from the intake survey and Annual Survey 1. Because our focus was on pediatrician choice to pursue subspecialty training, the small group of pediatricians who are surgical or other specialists and who did not train in a categorical or combined pediatrics residency program and pediatricians currently in fellowship training were excluded (final study sample size $=842$ ). The study was approved by the AAP Institutional Review Board.

\section{Survey Content}

Steps taken to develop PLACES survey content included 1) content prioritization by a project advisory committee, 2) literature review to identify related, existing questions, and 3) cognitive interviews and pilot tests to ensure that questions were interpreted correctly by respondents. ${ }^{10}$ Participants completed a two-page demographic survey and Annual Survey 1, a 12-page survey with many questions adapted from other physician studies, ${ }^{11-35}$ including the

Physician Worklife Study, ${ }^{28,33}$ MEMO study, ${ }^{23}$ Jefferson Scale of Lifelong Learning, ${ }^{11,35}$ study of female emergency physicians, ${ }^{17}$ national surveys, ${ }^{12,22,27}$ and AAP Periodic Survey of Fellows. ${ }^{15}$

\section{Measure of Fellowship Training}

The 842 pediatricians in this study were categorized into 2 groups: fellowship-trained and generalist-trained (did not pursue fellowship training), based on whether they reported that they previously had a fellowship position following residency and/or were board-certified or board 
eligible in a subspecialty. The fellowship-trained group is based on pediatrician's participation in fellowship training rather than their current position (e.g., generalist or subspecialist). Data were examined for work and life differences among those who pursued fellowship compared with those who did not, referred to as fellowship-trained and generalist-trained for consistency purposes.

\section{Analysis Weights}

Study participants were compared to the target sample and to data from the American Board of Pediatrics website, using t-tests and 1-sample proportion tests. Participants were significantly more likely to be female, AAP members, and graduates of U.S. medical schools. ${ }^{10}$ We calculated non-response and poststratification weights ${ }^{36}$ and applied a combined weight to all analyses presented in this paper.

\section{Data Analysis}

Data were analyzed for work and life differences between the fellowship-trained and generalist-trained groups. All comparisons represent differences between these two groups. Chi-square and t-tests were used to compare demographic characteristics, work environment, learning characteristics, work-life balance, financial characteristics, and satisfaction between fellowship-trained and generalist-trained pediatricians. For the continuous outcome variables, we dichotomized responses based on the distribution (e.g., mean) and for the categorical variables, we collapsed the first two responses of each scale (e.g., strongly agree and agree) and compared them to the other responses (e.g., strongly disagree and disagree). 
Multivariable logistic and linear regression models examined the independent association of fellowship training with work environment, learning characteristics, work-life balance, financial characteristics, and satisfaction while controlling for demographic characteristics (gender, race, marriage, children, and medical school location). Adjusted odds ratios (aOR), parameter estimates, and 95\% confidence intervals (CI) are presented to indicate the magnitude of the independent associations. The number of cases in each analysis varied slightly because of missing values for specific questions. All data presented, including numbers, are weighted as described above; $\mathrm{p} \leq .05$ was used for all analyses.

\section{RESULTS}

Of the 842 study participants, 39.0\% reported that they participated in fellowship training (fellowship-trained group). The most common subspecialties that fellowship-trained pediatricians were either board certified or board eligible in were the following: neonatalperinatal medicine (15.4\%), hematology-oncology (15.3\%), gastroenterology (9.2\%), critical care (8.3\%), cardiology (7.4\%), emergency medicine (6.8\%), allergy (5.5\%), pulmonology (4.6\%), endocrinology (4.4\%), developmental-behavioral pediatrics (3.8\%), infectious disease (3.8\%), nephrology (3.5\%), and genetics (3.4\%).

\section{Demographic Characteristics}

Sixty-three percent of the study pediatricians were women. The majority were white, non-Hispanic (62.5\%). Most (83.9\%) have children. At recruitment half of the pediatricians were not members of the AAP. 
Pediatrician demographics varied between the fellowship-trained and generalist-trained groups (Table 1). The largest difference showed there were more women in the generalisttrained group compared to the fellowship-trained group (68.5\% vs 53.0\%, $\mathrm{p}<.001)$.

\section{Work Environment}

The fellowship-trained group had over 4 times the odds (aOR=4.62; 95\% CI=3.32-6.42) of the generalist-trained group of working $\geq 50$ hours per week (Table 2). Fellowship-trained pediatricians were less likely to work part-time hours and in suburban areas $(\mathrm{p}<.001)$ and more likely to spend time in research, administration and teaching $(\mathrm{p}<.001)$. They also reported a lower percentage of time in a typical work week spent on direct patient care than those in the generalist-trained group (19.55 fewer percentage points, 95\% CI=-22.84- -16.25).

When asked about the proportion of their time that is spent in general pediatric and subspecialty care, most fellowship-trained pediatricians (77.6\%) reported spending at least half of their clinical time in subspecialty care with $23.4 \%$ spending at least a portion of their time in general pediatric care. Most of the pediatricians in the generalist-trained group (90.0\%) reported spending at least half of their clinical care time in general pediatric care, with $4.9 \%$ spending at least a portion of their time in subspecialty care.

\section{Learning Characteristics}

Fellowship-trained pediatricians were significantly more likely than the generalist group to strongly agree or agree that they routinely participate in continuing medical education (CME), routinely communicate with colleagues to gain new knowledge/skills, and that their current work 
allows them adequate opportunity to gain new knowledge and skills, $\mathrm{p}<.001$ (Table 3). All pediatricians were equally likely to make time for self-directed learning.

\section{Work-life Balance}

Fellowship-trained pediatricians were significantly less likely to agree that their schedule allows the flexibility needed to lead a balanced lifestyle (aOR=0.64; 95\% $\mathrm{CI}=0.48-0.86$ ) and to be satisfied with the amount of time they have to spend with their spouse, partner or significant other $(\mathrm{aOR}=0.68 ; 95 \% \mathrm{CI}=0.51-0.92)$ or their own children $(\mathrm{aOR}=0.62 ; 95 \% \mathrm{CI}=0.46-0.85)$ (Table 4). They were more likely to work in a somewhat hectic or hectic/chaotic work setting, (aOR=1.88; 95\% CI=1.40-2.53). Pediatricians in both groups were equally likely to agree that their colleagues support their efforts to balance personal and work responsibilities.

\section{Financial Characteristics}

Fellowship-trained and generalist-trained pediatricians reported similar amounts of education debt at completion of residency (\$80,815 and $\$ 80,762$, respectively) and at the time of being surveyed in 2012 (\$40,084 and \$38,650, respectively) (Table 5). Fellowship-trained pediatricians were more likely than the generalist group to report an annual income of $\$ 150,000$ or higher (66.6\% vs 53.3\%, $\mathrm{p}<.001)$. This difference disappeared when part-time pediatricians were excluded (Figure 1).

\section{Satisfaction}

Over $90 \%$ of pediatricians in both the fellowship-trained group and the generalist-trained group were satisfied with their training during residency (Table 5). The majority in both groups 
also found their present work to be personally rewarding and were satisfied with their life as a whole. Fellowship-trained and generalist-trained pediatricians were equally likely to report satisfaction with their residency training, present work, and life as a whole.

\section{DISCUSSION}

Using data from the AAP Pediatrician Life and Career Experience Study, collected in 2012, we found that 39\% of pediatricians who graduated residency between 2002 and 2004 pursued fellowship training. Fellowship-trained pediatricians were more likely than generalisttrained pediatricians to report working more hours per week, spending their time in research, administration, and medical teaching, and having opportunities at work and with colleagues to gain new knowledge and skills. Generalist-trained pediatricians were more likely to spend their time in direct patient care and have flexible work schedules and time with their spouse/partner and/or children. Most fellowship-trained and generalist-trained pediatricians were satisfied with their residency training, present work, and life as a whole.

The results of our study are both unique and complement existing literature on predictors and motivators for pursuing fellowship training. We found that men were more likely than women to pursue fellowship, as previously reported, ${ }^{1,2}$ but we did not find any significant differences for medical school location. Unique findings from the current study focus on work environment, learning, additional financial characteristics, work-life balance and overall satisfaction with residents' career choices. Pediatricians choosing to pursue fellowship are more likely to work at least 50 hours per week. Even several years after fellowship training is complete, they have over four times the odds of working more hours. Similarly, they are less 
likely to work part-time. A 2010 study of pediatricians of various ages found an increase in parttime work from 2000 to 2006 for both generalists and subspecialists, with $26 \%$ of generalists and $17 \%$ of subspecialists reporting part-time positions in $2006 .{ }^{37}$ In our cohort limited to early career fellowship-trained pediatricians, somewhat less, 14\%, reported part-time positions, and an increasing number of generalist-trained pediatricians work part-time (33\%) compared to the broader cohort in the earlier study. ${ }^{37}$ The PLACES study will continue to follow this group of early career pediatricians over time to better define changes in full or part-time work status over both generalist-trained and subspecialist-trained careers.

Pediatricians who are fellowship-trained are more likely to routinely participate in CME and communicate with colleagues to gain new knowledge/skills. Working in suburban practices and part-time might reduce the opportunities that generalist-trained pediatricians have for collegial interactions and regular CME participation. Many fellowship-trained pediatricians are more likely to practice in academic or hospital settings, perhaps providing more accessible educational opportunities. It may also be that learning new procedures is more important for some subspecialties. Although CME opportunities are generally plentiful even in the private practice setting, generalist-trained pediatricians should be aware of potential challenges for continued education post-residency.

Income level varied between the fellowship-trained and generalist-trained groups when part-time pediatricians were included in the analyses. When only full-time pediatricians were examined we did not find a difference. Rochlin and Simon examined the financial impact of fellowship training in pediatrics and reported that fellowships in cardiology, critical care, or neonatology provided greater "financial returns" than not pursuing fellowship but that training in other areas did not yield such results. ${ }^{38}$ 
Pediatric residents choosing whether or not to pursue fellowship training require information on their future work environment and responsibilities to make informed decisions. The experience of PLACES participants show that pediatricians in the fellowship-trained and generalist-trained groups reported that most of their direct patient care time was in subspecialty care and general pediatric care, respectively. However, almost a quarter of those in the fellowship-trained group reported at least a portion of their time was spent in general pediatric care. The fellowship-trained group is a diverse group, including pediatricians who practice in a variety of hospital based and clinic based subspecialties. From the PLACES survey we can not specify whether the general pediatric care reported is provided in the course of a subspecialty practice or as a separate position (for instance a neonatologist might provide some general pediatric care in a NICU follow up clinic as part of their subspecialty work versus a neonatologist who sees general pediatric patients in a pediatric clinic setting one day a week). Although our data provide some indication to residents of differences that emerge between those who do and do not pursue fellowships, future analyses might focus on the roles various subspecialists play in general pediatric care and which subspecialties contribute the most time to that type of care.

Studies have reported various motivators for pursuing careers as generalists including market forces, indebtedness, and work hours or availability of part-time positions. ${ }^{3,5,6}$ One study of graduating pediatric residents found that higher debt may lead residents to choose careers not requiring fellowship training, such as primary care or hospitalists. ${ }^{3}$ A recent study of general pediatricians found that only $9 \%$ cited consideration of debt as the most important factor in their choice of positions following residency. ${ }^{7}$ There was no difference in educational debt by fellowship group for pediatricians in our study, but debt has risen substantially over the last 
several years ${ }^{3,14}$ and could potentially be an important piece of information to those residents who are concerned about the financial implications of choosing further training in fellowship.

Structured hours/lifestyle was previously found to be a leading factor in career choice, particularly amongst female residents and those that were further in residency training. ${ }^{2}$ In the current study, generalist-trained pediatricians (those who never pursued fellowship training) reported more flexible schedules and greater satisfaction with time to spend with their spouse/partner/significant other and children. Achieving an acceptable work-life balance can be a major consideration of pediatric residents contemplating career choices, and supporting efforts to balance fellows' personal and work-life may need to be reexamined by fellowship training programs.

Freed et al reported that the majority of pediatric residents choosing fellowship training considered their residency training to be adequate preparation for fellowship. ${ }^{9}$ Other research found that most residents (94\%) graduating between 2003 and 2009 would choose a pediatric residency again, if they had a choice, and the majority rated their residency as very good or excellent in preparing them for primary care practice and fellowship training. ${ }^{39}$ In the current study most pediatricians (in both fellowship-trained and generalist-trained groups) reported being satisfied with training they received during residency

\section{Limitations}

There are limitations to the current study. All data are self-reported by the pediatricians. Some selection bias in terms of initial participation in the study exists but we adjusted for the bias by applying weights to all analyses. Our fellowship-trained group is based on the pursuit of fellowship and not completion of fellowship or current position. We found that some 
pediatricians who pursued fellowship are not exclusively practicing their subspecialty, and that pediatricians who did not pursue fellowship are at times practicing subspecialty care. Moreover, many different subspecialties were combined together to form a single group. It is impossible from the study design to determine what changes may be the direct result of the training experience.

\section{Conclusion}

While there are significant differences in work environment, educational pursuits, financial characteristics and work-life balance for pediatricians who choose fellowship and those who do not, overall life and career satisfaction is achieved by the majority of pediatricians. The differences could be considered by pediatric residents considering career options and by those advising and mentoring residents. The longitudinal nature of PLACES will allow further examination and insight into career and life experiences of those who pursued fellowship compared to those who did not across time.

\section{Acknowledgements}

We are most grateful to the pediatricians participating in PLACES and the project advisory committee who are all giving generously of their time to make this project possible. PLACES is funded by the AAP. 


\section{REFERENCES}

1. Pan RJ, Cull WL, Brotherton SE. Pediatric residents' career intentions: data from the leading edge of the pediatrician workforce. Pediatrics. 2002;109(2):182-188.

2. Freed GL, Dunham KM, Jones MD, Jr, McGuinness GA, Althouse L, Research Advisory Committee of the American Board of Pediatrics. General pediatrics resident perspectives on training decisions and career choice. Pediatrics. 2009;123(1 suppl):S26-30.

3. Frintner MP, Mulvey HJ, Pletcher BA, Olson LM. Pediatric resident debt and career intentions. Pediatrics. 2013;131(2):312-318.

4. Umoren RA, Frintner MP. Do mentors matter in graduating pediatric residents' career choices? Acad Peds. 2014;14(4):348-352.

5. $\quad$ Stoddard JJ, Cull WL, Jewett EA, Brotherton SE, Mulvey HJ, Alden ER. Providing pediatric subspecialty care: a workforce analysis. AAP Committee on Pediatric Workforce Subcommittee on Subspecialty Workforce. Pediatrics. 2000;106(6):13251333.

6. Cull WL, Caspary GL, Olson LM. Many pediatric residents seek and obtain part-time positions. Pediatrics. 2008;121(2):276-281.

7. Freed GL, Dunham KM, Switalski KE, Jones MD, Jr, McGuinness GA. Recently trained pediatric subspecialists: perspectives on training and scope of practice. Pediatrics. 2009;123(1 suppl):S44-49.

8. Freed GL, Dunham KM, Switalski KE, Jones MD, Jr, McGuinness GA. Recently trained general pediatricians: perspectives on residency training and scope of practice. Pediatrics. 2009;123(1 suppl):S38-43.

9. Freed GL, Dunham KM, Switalski KE, Jones MD, Jr, McGuinness GA. Pediatric fellows: perspectives on training and future scope of practice. Pediatrics. 2009;123(1 suppl):S31-37.

10. Frintner MP, Cull WL, Byrne BJ, et al. A longitudinal study of pediatricians early in their careers: PLACES. Under review.

11. Hojat M, Nasca TJ, Erdmann JB, Frisby AJ, Veloski JJ, Gonnella JS. An operational measure of physician lifelong learning: its development, components and preliminary psychometric data. Med Teach. 2003;25(4):433-437.

12. Centers for Disease Control and Prevention, National Health Interview Survey. 2011 National Health Interview Survey Questionnaire - Adult Health Behaviors. Document Version Date: 30-May-12. 2012; ftp://ftp.cdc.gov/pub/Health_Statistics/NCHS/Survey_Questionnaires/NHIS/2011/Englis h/qadult.pdf. Accessed May 31, 2013.

13. Shrestha D, Joyce CM. Aspects of work-life balance of Australian general practitioners: determinants and possible consequences. Aust J Prim Health. 2011;17(1):40-47.

14. American Academy of Pediatrics, Department of Research. Annual Survey of Graduating Residents. http://www.aap.org/en-us/professional-resources/Research/pediatriciansurveys/Pages/Annual-Survey-of-Graduating-Residents.aspx. Accessed May 31, 2013.

15. American Academy of Pediatrics, Department of Research. Periodic Survey of Fellows: pediatricians' practice and personal characteristics: US only, 2013. http://www.aap.org/en-us/professional-resources/Research/pediatriciansurveys/Pages/Personal-and-Practice-Characteristics-of-Pediatricians-US-only2010.aspx. Accessed January 23, 2012. 
16. American Board of Emergency Medicine. Longitudinal Study of Emergency Physicians. 2011; https://www.abem.org/public/home. Accessed May 31, 2013.

17. Clem KJ, Promes SB, Glickman SW, et al. Factors enhancing career satisfaction among female emergency physicians. Ann Emerg Med. 2008;51(6):723-728 e728.

18. Schoen C, Osborn R, Doty MM, Squires D, Peugh J, Applebaum S. A survey of primary care physicians in eleven countries, 2009: perspectives on care, costs, and experiences. Health Aff (Millwood). 2009;28(6):w1171-1183.

19. DeVoe J, Fryer Jr GE, Hargraves JL, Phillips RL, Green LA. Does career dissatisfaction affect the ability of family physicians to deliver high-quality patient care? J Fam Pract 2002;51(3):223-228.

20. Frank E, McMurray JE, Linzer M, Elon L. Career satisfaction of US women physicians: results from the Women Physicians' Health Study. Society of General Internal Medicine Career Satisfaction Study Group. Arch Intern Med. 1999;159(13):1417-1426.

21. Kravitz RL, Leigh JP, Samuels SJ, Schembri M, Gilbert WM. Tracking career satisfaction and perceptions of quality among US obstetricians and gynecologists. Obstet Gynecol. 2003;102(3):463-470.

22. Institute for Social Research, Survey Research Center, University of Michigan. Panel Study of Income Dynamics. http://psidonline.isr.umich.edu/. Accessed December 4, 2014.

23. Linzer M, Baier Manwell L, Mundt M, et al. Organizational climate, stress, and error in primary care: The MEMO Study. In: Advances in patient safety: from research to implementation. AHRQ Publication No. 050021 (1). Rockville, MD: Agency for Healthcare Research and Quality; 2005, vol. 1:65-77.

24. Linzer M, Konrad TR, Douglas J, et al. Managed care, time pressure, and physician job satisfaction: results from the Physician Worklife Study. J Gen Intern Med. 2000;15(7):441-450.

25. Linzer M, Gerrity M, Douglas JA, McMurray JE, Williams ES, Konrad TR. Physician stress: results from the Physician Worklife Study. Stress and Health. 2002;18(1):37-42.

26. McMurray JE, Linzer M, Konrad TR, Douglas J, Shugerman R, Nelson K. The work lives of women physicians results from the Physician Worklife Study. The SGIM Career Satisfaction Study Group. J Gen Intern Med. 2000;15(6):372-380.

27. National Center for Health Statistics. Health Indicators Warehouse. Sufficient sleep: adults.

http://www.healthindicators.gov/Indicators/Sufficientsleepamongadults_1472/Profile/Dat a. Accessed January 19, 2013.

28. Williams ES, Konrad TR, Linzer M, et al. Physician, practice, and patient characteristics related to primary care physician physical and mental health: results from the Physician Worklife Study. Health Serv Res. 2002;37(1):121-143.

29. American Board of Pediatrics. Maintenance of Certification Application Survey. 2013; https://www.abp.org/. Accessed July 11, 2013.

30. The University of Melbourne. Medicine in Australia: Balancing Employment and Life (MABEL). https://mabel.org.au/. Accessed August 31, 2011.

31. Centers for Disease Control and Prevention, Ambulatory Health Care Data. National Ambulatory Medical Care Survey. http://www.cdc.gov/nchs/dhcs/dhcs_surveys.htm. Accessed July 11, 2011. 
32. Boukus E, Cassil A, O'Malley AS. A snapshot of U.S. physicians: key findings from the 2008 Health Tracking Physician Survey. Data Bulletin (Center for Studying Health System Change). 2009(35):1-11.

33. Williams ES, Konrad TR, Linzer M, et al. Refining the measurement of physician job satisfaction: results from the Physician Worklife Survey. SGIM Career Satisfaction Study Group. Society of General Internal Medicine. Medical Care. 1999;37(11):1140-1154.

34. Center for Studying Health System Change. Community Tracking Study Physician Survey. http://www.hschange.org. Accessed July 11, 2011.

35. Hojat M, Veloski JJ, Gonnella JS. Measurement and correlates of physicians' lifelong learning. Acad Med. Aug 2009;84(8):1066-1074.

36. Groves R, Fowler F, Couper M, Lepkowski J, Singer E, Tourangeau R. Survey Methodology, Second Edition. Hoboken, New Jersey: John Wiley and Sons, Inc; 2009.

37. Cull WL, O'Connor KG, Olson LM. Part-time work among pediatricians expands. Pediatrics. January 1, 2010 2010;125(1):152-157.

38. Rochlin JM, Simon HK. Does fellowship pay: what is the long-term financial impact of subspecialty training in pediatrics? Pediatrics. 2010;127(2):254-260.

39. Frintner MP, Cull WL. Pediatric training and career intentions, 2003-2009. Pediatrics. 2012;129(3):522-528. 
Table 1. Pediatrician Demographics: Fellowship-Trained vs Generalist-Trained

\begin{tabular}{|l|c|c|c|}
\hline & $\begin{array}{c}\text { Fellowship- } \\
\text { Trained } \\
\mathrm{n}=328\end{array}$ & $\begin{array}{c}\text { Generalist- } \\
\text { Trained } \\
\mathrm{n}=514\end{array}$ & p \\
\hline Women, \% & 53.0 & 68.5 & $<.001$ \\
\hline Race, \% & & & $<.01$ \\
\hline White, non-Hispanic & 65.9 & 60.3 & \\
\hline Asian & 20.4 & 18.7 & \\
\hline Hispanic & 9.8 & 10.3 & \\
\hline Black or African American & 3.0 & 6.0 & \\
\hline Other & 0.9 & 4.7 & \\
\hline Married, \% & 87.2 & 91.5 & .046 \\
\hline Have children, \% & 80.8 & 85.8 & .053 \\
\hline Medical School Outside U.S. (IMG), \% & 21.3 & 19.1 & .420 \\
\hline
\end{tabular}


Table 2. Work Environment: Fellowship-Trained vs Generalist-Trained

\begin{tabular}{|c|c|c|c|}
\hline & $\begin{array}{c}\text { Fellowship- } \\
\text { Trained } \\
\mathrm{n}=322 \\
\end{array}$ & $\begin{array}{c}\text { Generalist- } \\
\text { Trained } \\
\text { n = 498 } \\
\end{array}$ & aOR, 95\% CI \\
\hline Work $\geq 50$ hours per week, $\%$ & 60.6 & $23.4^{*}$ & $4.62,3.32-6.42^{* *}$ \\
\hline Work part-time, \% & 13.7 & $33.3^{*}$ & $0.34, .22-.53^{* *}$ \\
\hline Work in suburban area, \% & 18.1 & $51.1^{*}$ & $0.21,0.15-0.30^{* *}$ \\
\hline Ever on call, \% & 83.4 & 78.1 & $1.41,0.97-2.06$ \\
\hline \multirow{2}{*}{$\begin{array}{l}<7 \text { hours of sleep per } 24 \text {-hour } \\
\text { period }\end{array}$} & 30.2 & 25.9 & $1.20,0.87-1.65$ \\
\hline & $\begin{array}{c}\text { Fellowship- } \\
\text { Trained } \\
\text { n = 322 } \\
\end{array}$ & $\begin{array}{c}\text { Generalist- } \\
\text { Trained } \\
\text { n }=498\end{array}$ & $\begin{array}{c}\text { Parameter estimate, } \\
95 \% \text { CI }\end{array}$ \\
\hline $\begin{array}{l}\text { Time spent in direct patient care, } \\
\text { mean } \%\end{array}$ & 67.9 & $87.6^{*}$ & $-19.55,-22.84--16.25^{* *}$ \\
\hline Time spent in research, mean \% & 14.2 & $0.7^{*}$ & $13.46,11.37-15.55^{* *}$ \\
\hline $\begin{array}{l}\text { Time spent in administration, } \\
\text { mean \% }\end{array}$ & 10.5 & $7.1^{*}$ & $3.16,1.45-4.87^{* *}$ \\
\hline $\begin{array}{l}\text { Time spent in medical teaching, } \\
\text { mean } \%\end{array}$ & 5.8 & $2.6^{*}$ & $3.16,2.12-4.21^{* *}$ \\
\hline $\begin{array}{l}\text { Time spent in other activities, } \\
\text { mean \% }\end{array}$ & 1.6 & 2.0 & $-0.18,-1.80-1.45$ \\
\hline
\end{tabular}

* Chi-square $\mathrm{p} \leq .05$; ** regression $\mathrm{p} \leq .05$; aOR $=$ adjusted odds ratio; $\mathrm{CI}=$ confidence interval. Each model controls for the fellowship group as well as gender, race, married, have children, and medical school location. 
Table 3. Learning Characteristics: Fellowship-Trained vs Generalist-Trained

\begin{tabular}{|l|c|c|c|}
\hline & \multicolumn{2}{|l|}{} \\
\hline & $\begin{array}{c}\text { Fellowship- } \\
\text { Trained } \\
\mathrm{n}=328\end{array}$ & $\begin{array}{c}\text { Generalist- } \\
\text { Trained } \\
\mathrm{n}=511\end{array}$ & aOR, 95\% CI \\
\hline $\begin{array}{l}\text { I routinely communicate with colleagues to } \\
\text { gain new knowledge/skills, \% strongly } \\
\text { agree/agree }^{\mathrm{A}}\end{array}$ & 95.7 & $84.9^{*}$ & $4.02,2.25-7.26^{* *}$ \\
\hline $\begin{array}{l}\text { I routinely participate in continuing medical } \\
\text { education, \% strongly agree/agree }\end{array}$ & 89.6 & $83.1^{\mathrm{A}}$ & $1.67,1.08-2.57^{* *}$ \\
\hline $\begin{array}{l}\text { My current work allows me adequate } \\
\text { opportunity to gain new knowledge and skills }\end{array}$ & 84.0 & $74.6^{*}$ & $1.62,1.12-2.34^{* *}$ \\
\hline $\begin{array}{l}\text { I routinely make time for self-directed } \\
\text { learning, \% strongly agree/agree }\end{array}$ & 75.3 & 71.0 & $1.23,0.89-1.71$ \\
\hline
\end{tabular}

* Chi-square $\mathrm{p} \leq .05 ; * *$ regression $\mathrm{p} \leq .05$; aOR $=$ adjusted odds ratio; $\mathrm{CI}=$ confidence interval. Each model controls for the fellowship group as well as gender, race, married, have children, and medical school location.

A 4-point scale responses dichotomized: strongly agree/agree vs disagree/strongly disagree 
Table 4. Work-Life Balance: Fellowship-Trained vs Generalist-Trained

\begin{tabular}{|c|c|c|c|}
\hline & $\begin{array}{c}\text { Fellowship- } \\
\text { Trained } \\
\text { n = 328 } \\
\end{array}$ & $\begin{array}{c}\text { Generalist- } \\
\text { Trained } \\
n=512 \\
\end{array}$ & aOR, 95\% CI \\
\hline $\begin{array}{l}\text { Colleagues support efforts to balance } \\
\text { personal and work responsibilities, \% } \\
\text { agree or strongly agree }^{A}\end{array}$ & 71.1 & 67.9 & $1.10,0.80-1.50$ \\
\hline $\begin{array}{l}\text { Schedule allows flexibility to lead } \\
\text { balanced life, } \% \text { agree or strongly }^{\text {agree }^{\mathrm{A}}}\end{array}$ & 53.8 & $64.3^{*}$ & $0.64,0.48-0.86^{* *}$ \\
\hline $\begin{array}{l}\text { Busyness of work setting, \% } \\
\text { somewhat hectic or hectic/chaotic }{ }^{B}\end{array}$ & 52.8 & $38.0^{*}$ & $1.88,1.40-2.53 * *$ \\
\hline $\begin{array}{l}\text { Amount of time to spend with own } \\
\text { children, \% satisfied or very satisfied }\end{array}$ & 46.7 & $58.8^{*}$ & $0.62,0.46-0.85 * *$ \\
\hline $\begin{array}{l}\text { Amount of time to spend with } \\
\text { spouse/partner/sig other, } \% \text { satisfied } \\
\text { or very satisfied }^{\text {C }}\end{array}$ & 45.6 & 52.6 & $0.68,0.51-0.92 * *$ \\
\hline
\end{tabular}

* Chi-square $\mathrm{p} \leq .05$; ** regression $\mathrm{p} \leq .05$; aOR $=$ adjusted odds ratio; $\mathrm{CI}=$ confidence interval. Each model controls for the fellowship group as well as gender, race, married, have children, and medical school location.

A5-point scale responses dichotomized: strongly agree/agree vs neither agree nor disagree/disagree/strongly disagree; ${ }^{\text {B5}}$-point scale responses dichotomized: hectic, chaotic/somewhat hectic vs busy, but reasonable/somewhat calm/calm; ${ }^{{ } 5}$-point scale responses dichotomized: very satisfied/satisfied vs neutral/dissatisfied/very dissatisfied 
Table 5. Financial and Satisfaction: Fellowship-Trained vs Generalist-Trained

\begin{tabular}{|c|c|c|c|}
\hline & $\begin{array}{c}\text { Fellowship- } \\
\text { Trained } \\
\text { n = 322 }\end{array}$ & $\begin{array}{c}\text { Generalist- } \\
\text { Trained } \\
\text { n }=507\end{array}$ & $\begin{array}{c}\text { Parameter } \\
\text { estimate, } 95 \% \text { CI }\end{array}$ \\
\hline $\begin{array}{l}\text { Mean educational debt at completion of } \\
\text { residency, } \$^{* * *}\end{array}$ & $\$ 80,815$ & $\$ 80,762$ & 1552, $-9603-12708$ \\
\hline \multirow{2}{*}{$\begin{array}{l}\text { Mean educational debt at time of } 2012 \\
\text { survey, } \text { \$*** }^{* *}\end{array}$} & $\$ 40,084$ & $\$ 38,650$ & 1998, -5818-9815 \\
\hline & $\begin{array}{c}\text { Fellowship- } \\
\text { Trained } \\
\text { n = 328 }\end{array}$ & $\begin{array}{c}\text { Generalist- } \\
\text { Trained } \\
n=513\end{array}$ & aOR, 95\% CI \\
\hline $\begin{array}{l}\text { Satisfied with training during residency, } \\
\% \text { very or somewhat satisfied }{ }^{\mathrm{A}}\end{array}$ & 93.6 & 91.4 & $1.39,0.80-2.42$ \\
\hline $\begin{array}{l}\text { I find my present work personally } \\
\text { rewarding, \% strongly agree or agree }{ }^{\mathrm{B}}\end{array}$ & 89.6 & 85.4 & $1.45,0.93-2.28$ \\
\hline $\begin{array}{l}\text { Satisfied with life as a whole, \% } \\
\text { completely or very satisfied }{ }^{\mathrm{C}}\end{array}$ & 69.8 & 74.3 & $0.79,0.57-1.09$ \\
\hline
\end{tabular}

* Chi-square $\mathrm{p} \leq .05$; ** regression $\mathrm{p} \leq .05$; $\mathrm{aOR}=$ adjusted odds ratio; $\mathrm{CI}=$ confidence interval. Each model controls for the fellowship group as well as gender, race, married, have children, and medical school location.

$* * *$ Includes some pediatricians without any debt $(\$ 0)$

${ }^{A} 5$-point scale responses dichotomized: very satisfied/somewhat satisfied vs neither satisfied nor unsatisfied/somewhat unsatisfied/very unsatisfied; ${ }^{\mathrm{B}} 5$ point scale responses dichotomized: strongly agree/agree vs neither agree nor disagree/disagree/strongly disagree; ${ }^{C} 5$-point scale responses dichotomized: completed satisfied/very satisfied vs somewhat satisfied/not very satisfied/not at all satisfied 
Figure 1. PLACES Pediatricians Income Categories by Fellowship Group

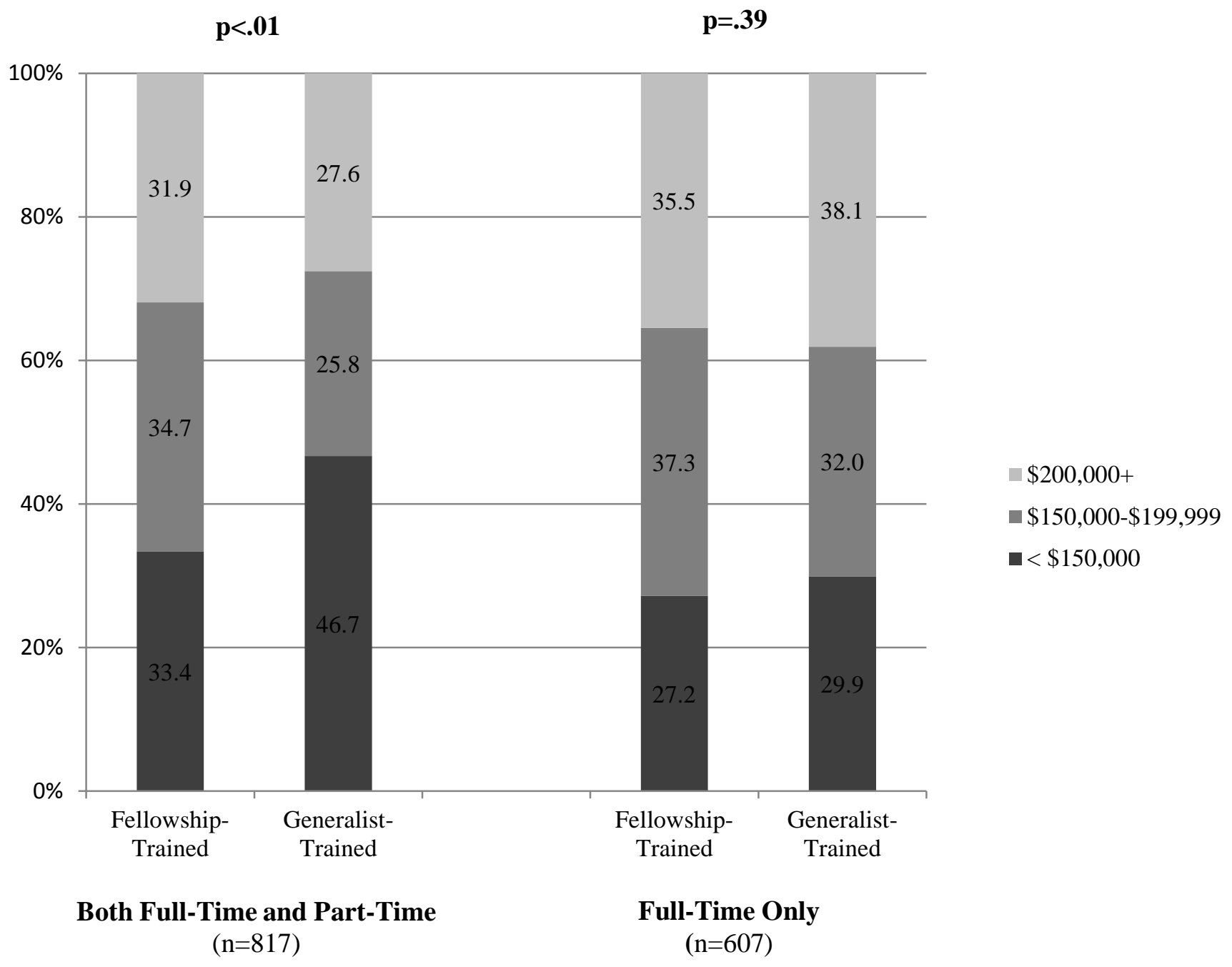

P value represents chi-square result for comparison of income group and fellowship group 